\title{
MAKING TRANSDISCIPLINARITY WORK
}

\author{
An epistemology of inclusive \\ development and innovation
}

\section{David Ludwig and Birgit K. Boogaard}

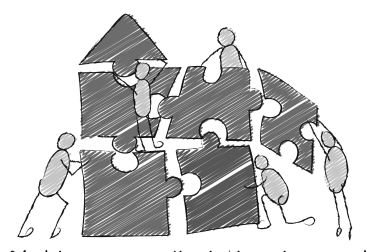

Making transdisciplinarity work

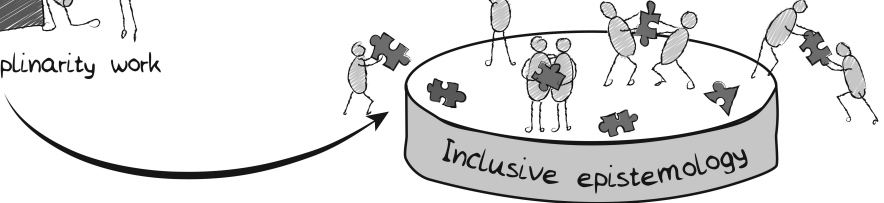

\section{Introduction}

'Development' and 'innovation' are concepts in perpetual crisis. After almost 30 years of post-development discourse (Asher and Wainwright, 2019; Escobar, 1991; Sachs, 1992), there is little shock value in challenging development as a concept that has contributed to global inequality and environmental destruction by pushing agendas of economic growth and modernisation onto the Global South. The concept of innovation has also long lost its innocence. While innovation narratives often appeal to depoliticised and supposedly neutral notions of progress, it has been widely argued that innovation discourses strategically highlight certain practices and technologies that reinforce growth- and 
modernisation-oriented development agendas (Blok and Lemmens, 2015; Ludwig and Macnaghten, 2020).

There is no shortage of attempts to reimagine both development and innovation by making them more inclusive, responsible, participatory, social, and sustainable (Heeks, Foster, and Nugroho, 2014; Pansera and Owen, 2018; Siddiqi and Collins, 2017; Stilgoe, Owen, and Macnaghten, 2013). Despite this diversity of frameworks, development and innovation scholars commonly emphasise the need to shift target outcomes from an exclusive focus on economic growth to the inclusion of societal and environmental concerns (Chataway, Hanlin, and Kaplinsky, 2014; Gupta and Vegelin, 2016). At the same time, it is not sufficient to swap target outcomes in a top-down process that fails to include affected stakeholders in the negotiations of these targets and the pathways of achieving them. This chapter focuses on the epistemic conditions of this process of reimagination by addressing different forms of knowledge and their interactions in transdisciplinary approaches to development and innovation.

Attempts to reimagine development and innovation have become closely connected to wider debates about inclusive strategies for knowledge production that are framed through 'collaboration,' 'co-creation,' 'citizen science,' 'intercultural dialogue,' 'interdisciplinarity,' 'multi-stakeholder platforms,' 'participatory design,' 'participatory action research,' 'science society dialogue,' 'transdisciplinarity,' 'public engagement,' and 'open science.' While all of these notions have different genealogies, they are connected through an overall concern with opening up knowledge production and research processes for input from heterogeneous actors. This chapter focuses on transdisciplinarity as arguably the most developed framework for reimagining the epistemology of inclusive development and innovation beyond a mere change of target outcomes.

The need for transdisciplinary approaches has been widely emphasised in the development domain and is commonly motivated by social-environmental challenges that are not suited for narrow disciplinary solutions but require negotiation and heterogeneous forms of situated knowledge (Brown, Harris, and Russel, 2010; OECD, 2020; Pohl, Truffer, and Hadorn, 2017). The following section motivates this move towards transdisciplinarity by interpreting two case studies of agricultural development projects as studies of epistemic failures. The section thereafter builds on this analysis through introducing transdisciplinarity as an inclusive epistemology that has the potential to integrate heterogeneous forms of situated knowledge in the negotiation of social-environmental change. While transdisciplinarity takes knowledge diversity seriously, we argue that its integrationist agenda has been limited by both methodological, political, and historical factors, in which there continues to be a hegemony of Global North epistemologies over Indigenous and local epistemologies on account of a complex fusion of colonial legacy, scientism, and unequal power relations. For decades 'decolonisation' of knowledge has been addressed by post-development scholars (amongst many, see Escobar, 1991) and African philosophers (amongst many, see Wiredu, 1995), and over the past years is gaining increased attention 
by a wider audience in academia and beyond (see, for example, Brahma et al., 2018). However, the underlying questions of how to bring a diversity of epistemologies, ontologies, and values together are far from straightforward. Making transdisciplinarity work requires moving beyond an integrationist agenda that recognises knowledge diversity only insofar as it can be accommodated in a shared academic framework. Knowledge integration matters, but a critical transdisciplinarity also needs to engage with its limitations through transformative dialogues about epistemology, ontology, and values.

\section{Epistemic failures in agricultural development projects}

The agricultural modernisation paradigm in which 'traditional' ways of farming are viewed as in need of transformation to more 'modern' ways of farmingwith improved productivity, increased specialisation, at larger scale, leading to increased farmer incomes - has been imposed on smallholder farmers across the globe. This paradigm has been widely criticised, because the arsenal of agricultural modernisation innovations - machines, fertilisers, pesticides, seed varieties - often opened countries to a global agri-food industry that left environments degraded, traditional agricultural practices eroded, and smallholder farmers dispossessed (Van der Ploeg et al., 2000; McMichael, 2015). These critiques led to the desire to move away from the agricultural modernisation paradigm, and instead focus on community-led rural development (Van der Ploeg et al., 2000). In this line, there have been numerous approaches to make agricultural development more inclusive-ranging from participatory action research (PAR) to the formation of multi-stakeholder platforms-focused on agriculture's contributions to ensuring food security and improving livelihoods. However, the ideal of agricultural modernisation has not disappeared from the stage entirely and is still reflected in present-day agricultural development approaches and programmes, ranging from large-scale industrial agriculture initiatives to 'sustainable intensification' by smallholders. The aim of this section is not to provide an in-depth analysis of all critiques on agricultural modernisation, but rather to focus on the epistemic dimension of it, while recognising that this is but one mode of analysis and critique.

The wider characterisation of the agricultural modernisation paradigm as a neo-liberal perspective on development dominated by market institutions and formal market logic (van der Ploeg, 2009) interacts with a more specific assumption of an epistemic hierarchy between academic researchers and local communities. The 'firm belief in technological solutions and economic progress' (Boogaard, 2019, p. 275) in the agricultural modernisation paradigm often remained unquestioned because modern science and technology were positioned as the only valid source of knowledge for improving livelihoods, while at the same characterising local communities in terms of a knowledge deficit. This section will focus on how this assumption of an epistemic hierarchy created and reinforced epistemic failures by marginalising local forms of knowledge 
that are of crucial importance for responding to social-environmental challenges and for developing innovations that reflect the needs and perspectives of local communities. Epistemic failures can therefore be understood as symptoms of an underlying hierarchical epistemology that is inadequate for recognising and integrating a diversity of knowledges. In this sense, agricultural modernisation can be interpreted as producing: (1) epistemic failures that over-focus on academic knowledge while excluding the knowledge of local communities; and (2) a hierarchical epistemology that generates these failures through an assumption of the superiority of Global North epistemologies that structurally excludes Indigenous and local epistemologies. Two case studies are used to underpin these arguments: Lansing's (2009) study of rice farming in Bali, and Boogaard's (2021) study on epistemic injustice in a livestock development project in Mozambique.

Lasing's case study of agricultural modernisation discusses the effects of the so-called 'Green Revolution' on rice farming in Bali that was organised around water temples that would regulate the flow of water to subaks, systems of terraced paddy fields, through religious rituals. Green Revolution engineers, guided by a narrow focus on scientific knowledge, not only failed to recognise the functions of these religious practices but also dismissed the system as a whole as inefficient and in need of modernisation through agricultural innovations ranging from novel rice varieties to externally introduced pesticides to more efficiently organised irrigation schedules. Lansing (2009, p. 115) summarises this attitude by quoting a 'frustrated American irrigation engineer' claiming that 'these people don't need a high priest, they need a hydrologist!'

The narrow focus on externally produced scientific knowledge and the exclusion of local epistemic resources motivated a modernisation programme that turned into an ecological and social disaster. As Lansing (2015, p. 114) puts it,

The threat of legal penalties against anyone failing to grow the new rice led to continuous cropping of Green Revolution rice. Religious rituals continued in the temples, but field rituals no longer matched the actual stages of rice growth. As soon as one crop was harvested, another was planted, and cropping cycles began to drift apart. During [...] the dry season, the supply of irrigation water became unpredictable. Soon, district agricultural offices began to report 'chaos in the water scheduling' and 'explosions of pest populations.'

Lansing's computational modelling of water flows highlights two crucial functions of water temples. First, the rituals distributed water as a scarce resource by ensuring that subaks downstream would still receive sufficient water during the dry season. Second, the rituals coordinated the water temples, which controlled pest populations through synchronised watering and cropping schedules over hundreds of hectares. While Lansing's model suggests that the religious rituals led to an optimal balance of these two factors, the enforcement of an agricultural 
modernisation paradigm led to the breakdown of this system with the consequence of water shortages and pest outbreaks.

These above epistemic failures are not unique to rice farming in Bali, but are mirrored by agricultural development projects until today. The following case study is an ex-post analysis of a livestock development project in Mozambique (2011-2013) that aimed to improve goat keeping and marketing in the Inhassoro district in Mozambique. The project brought different stakeholders of the 'goat value chain' together in an innovation platform with the aim to jointly identify problems, search for solutions, and arrive at collective action. The case study did not evaluate the effectiveness of the project, but in retrospect looked at epistemic injustices, in the sense of the systematic and structural exclusion of Indigenous ways of knowing and doing. The study identified various ways in which epistemic injustice was maintained or reinforced (Boogaard, 2021); below we will mention three epistemic failures in this agricultural development project.

To begin, the project provided training on 'improved' goat keeping practices and marketing, based mainly on the transfer of academic knowledge. Indigenous knowledge, including of goat husbandry, was not considered as relevant by the project team. Through the framing of terms such as 'improved,' academic scientific knowledge and practices were (implicitly) regarded as superior to Indigenous knowledge (Van der Ploeg, 2016). Secondly, the case study reveals that epistemic injustice was produced not only directly through training and instruction, but also in more 'subtle' ways that included the ways in which the project imposed goals of commercialisation and modernisation onto rural goat keepers, in this case without recognising or addressing residual tensions between market-led thinking and Indigenous values and practice such as mutual assistance.

The one-sided focus of the project on the commercialisation of goat keeping reflects the underlying Global North development ideology of agricultural modernisation and commercialisation. This constitutes a form of epistemic paternalism in which Global North-led project organisations assume to know what is 'best' for the rural goat keepers: that in order to improve their livelihoods, they needed to commercialise goat keeping. In such ways, the project disregarded existing social structures and practices including the value of life as embedded in relationships of mutual assistance and aid that is commonplace in African philosophies (Wiredu, 2003; see also Boogaard and Van Norren, this volume). Thirdly, while rural goat keepers were included in the project through an innovation platform, the Global North-led project organisations had set the vision, conditions, definitions, borders, and some of the interventions at the start of the project, and these were not open for change or negotiation throughout the project. In that sense, the project was entrenched in Eurocentric thinking and doing, which had the effect of reinforcing unequal epistemological hierarchies in which Global North knowledge remained dominant over other types of knowledge. Overall, it can be concluded that the innovation platform included people but excluded their epistemology. Thus while in theory, 'inclusive innovation' and 'inclusive development' can offer space for 'knowledge co-creation' or 
'knowledge diversity,' in practice such platforms can become a vehicle that in fact reinforces dominant Global North epistemologies.

The cases of water temples in Bali and goat production in Mozambique provide complementary lessons about epistemic failures in development projects. Both programmes of agricultural modernisation were deeply steeped in epistemic paternalism in the sense that they recognised mainly the expertise of agricultural engineers and scientists while casually dismissing any epistemic resources of the affected communities. Local communities were recognised as beneficiaries of development interventions but not as epistemic actors with relevant knowledge of their own. In both cases, epistemic paternalism produced epistemic injustices in the sense of epistemology viewed as a social achievement (Kidd, Medina, Pohlhaus, 2017). Fricker (2007) distinguishes between testimonial and hermeneutic injustice, where the former refers to an unfair attribution of credibility and the latter refers to injustices in the epistemic resources in interpreting experiences and livelihoods. Epistemic paternalism produces widespread testimonial injustices as reflected in the lack of consideration of Indigenous knowledge about goat keeping and rice farming in Mozambique and Bali, respectively. Furthermore, both cases illustrate how development projects produce hermeneutic injustices by imposing concepts and frameworks that exclude local perspectives and practices, such as those on irrigation as practised through rituals in water temples in Bali and the entangled social and spiritual perspectives on mutual help that are commonplace among goat keepers in Mozambique.

\section{Transdisciplinarity as an inclusive epistemology}

The previous section highlighted problems of epistemic paternalism and epistemic injustice and how these were prevalent in development projects even in those that sought to include local communities in the formulation of target outcomes (for example, on 'improved' rice farming and goat keeping) but which at the same time excluded local knowledge and expertise. Transdisciplinarity has emerged as a widely embraced approach that promises to overcome these epistemic challenges by including heterogeneous stakeholders in the process of knowledge production (Lawrence, 2015; Scholz and Steiner, 2015). For example, a recent policy report from the OECD calls for a 'paradigm shift in research practice' and hails transdisciplinarity as a new mode of research 'that integrates both academic researchers from unrelated disciplines-including natural sciences and $\mathrm{SSH}$ - and non-academic participants to achieve a common goal, involving the creation of new knowledge and theory' (OECD, 2020, p. 9). The OECD report converges with the wider transdisciplinary literature (Cole, 2017; Schmidt and Pröpper, 2017) in highlighting the need to rethink knowledge production for development and innovation agendas. As we examine below, much of this transdisciplinary literature can be described as combining: (1) an ontological claim about the multi-dimensional and multi-scale nature of social-environmental problems; (2) an epistemological claim about the broad distribution of expertise 
about social-environmental problems; and (3) a methodological agenda of integrating diverse forms of expertise in addressing them.

First, transdisciplinarity is commonly motivated by pointing to the multidimensional nature of global challenges in the sense that they involve the interaction of a wide range of factors that have been traditionally studied by separate disciplines. For example, the challenge of global food production encompasses a wide range of heterogeneous factors that include the genetics of new crop varieties, the division of labour in agrarian communities, carbon emissions of livestock, profit margins of agricultural producers, soil erosion, food security and sovereignty of smallholder farmers, local culinary traditions, and deforestation and spiritual practices. Beyond this general observation that points to the need for multi-dimensional approaches in the sense of a large diversity of interacting factors, global challenges also exhibit a multi-scale character in the sense that they take different shapes at different local, regional, national, and global levels. The global challenge of 'feeding the world' materialises in very different ways for different actors (such as smallholder farmers, workers in a food processing plant, end consumers in a supermarket) and in different geographic contexts (for example, for farmers in Bali as compared to, say, Kansas). The multi-scale character of global challenges limits the usefulness of generic accounts of global challenges such as 'feeding the world' and rather challenges researchers to address a large variety of contextually variable and interacting factors.

Second, the multi-dimensional and multi-scale character of global challenges justifies an epistemology that emphasises the diversity of relevant epistemic actors. Multi-dimensionality requires interdisciplinary approaches that bring together epistemic resources from a wide range of disciplines. Agricultural development, for example, relates to the technical expertise of various disciplinary fields from plant breeding to water management to cultural anthropology to political economy. In the Balinese case study, for example, technical agricultural expertise was in dire need of interdisciplinary interaction with the social sciences and humanities to understand social practices and their interactions with local religious traditions. Furthermore, the multi-scale character of global challenges demonstrates the crucial role of non-academic actors and their situated knowledge about environmental and social contexts. For example, Mozambique and Bali do not exhibit identical dynamics in the interaction of environmental and social factors. As debates about Indigenous and local knowledge have highlighted (Berkes, 2018; Ludwig and Poliseli, 2018), local communities tend to be experts about the specificities of local social and environmental systems. Many relevant factors from local soil conditions to social division of labour are best understood by local community members while external researchers tend to struggle to grasp the nuances of local dynamics.

Third, this acknowledgement of distributed expertise leads to an integrationist methodology of bringing relevant actors together in transdisciplinary processes. In this sense, Scholz and Steiner (2015, p. 532) describe 'knowledge integration as the core of transdisciplinarity' and argue that the 'main added value of 
transdisciplinarity $[\ldots]$ is the integration or relationship of different forms of epistemics (i.e., ways of knowing). Whereas disciplines are brilliant at explaining specific aspects in a theoretical form, the major asset of transdisciplinarity is the merging and relating of different types of perception, knowledge, and valuations in an integrated manner.' In both the cases of Bali and Mozambique, such a process of integration would promise not only a more nuanced understanding of complex social-environmental dynamics, but also contribute to better development interventions that are responsive to cultural, economic, environmental, and social contexts.

\section{Transdisciplinary promises and transdisciplinary failures}

The transdisciplinary push for an inclusive epistemology can contribute to reimagining development and innovation through the recognition of diverse knowledge of heterogeneous actors, from laboratory scientists to farmers. Rather than thinking of 'inclusion' as a simple expansion or reconfiguration of target goals towards societal and environmental concerns, transdisciplinary frameworks allow a (re)conceptualisation of 'inclusion' at the deeper level of negotiating concerns and the process of how to achieve them.

Beyond such programmatic statements, however, it remains important to tell a more cautionary tale about transdisciplinarity in practice. It has been 50 years since the OECD put transdisciplinary on the agenda at its 1970 International Conference on Interdisciplinary Research and Education, and many promises of inclusive knowledge production remain mostly programmatic declarations. In fact, the implementation of transdisciplinary processes comes with challenges, as it is often 'difficult to reconcile the idea of knowledge co-production with research realities' (Schmidt and Pröpper, 2017, p. 365). Of course, there are many technical and organisational barriers in bringing together heterogeneous actors with limited funding, time frames, language barriers, lack of interest, and so on. However, the challenges of transdisciplinarity are not merely pragmatic and point towards two more fundamental shortcomings that arise from a simple integrationist agenda of transdisciplinarity. First, knowledge integration is only one aspect of a wider negotiation process, and an exclusive focus on integration runs the risk of obscuring epistemological and ontological tensions. Second, transdisciplinary models tend to incorporate idealised assumptions about the equality of actors and therefore run the risk of producing depoliticised frameworks that fail to address that integration often amounts to selective use and appropriation of knowledge between actors in vastly different positions of power (Healy, 2019).

There is no doubt that knowledge integration matters and can contribute to more just and inclusive development and innovation processes. In the case of Bali, the incorporation of Indigenous knowledge about irrigation schedules could have avoided water shortages and pest-spread that were managed through rituals in water temples. In the case of Mozambique, the inclusion of Indigenous knowledge of goat keepers could have led to a better understanding 
of goats as supporting mutual aid in communities rather than only focussing on commercialisation. Both cases provide clear examples of Indigenous knowledge that could have improved development interventions but which remained marginalised through the epistemic paternalism of expert-driven development projects. A transdisciplinary process that challenges these epistemic injustices through the recognition of distributed expertise could have detected these issues early on and avoided interventions that further harmed local communities.

While development practice illustrates the potential of knowledge integration, it provides at least as many cases of integration failures (Byskov, 2020). Reflective transdisciplinary practices need to avoid a simple additive model of knowledge integration. For example, Klein et al. (2001, p. 7) present transdisciplinarity through the idea that 'knowledge of all participants is enhanced, including local knowledge, scientific knowledge, and the knowledges of concerned industries, businesses, and non-governmental organisations (NGOs). The sum of this knowledge will be greater than the knowledge of any single partner.' However, knowledge often does not stack up like this and there is not an obvious 'sum of knowledge' that guides better development interventions. Instead, the knowledge of heterogeneous actors often creates tensions as it is embedded in different epistemic traditions, ontological assumptions, and value systems (Ludwig and El-Hani, 2020). Not everything that counts as knowledge from the perspective of one actor will be recognised as knowledge from the perspective of another actor. Transdisciplinarity is full of intellectual contestation, equivocation, misunderstanding, and tension.

Simple transdisciplinary agendas that employ an additive model of knowledge integration therefore run the risk of 'knowledge mining' (Kimmerer, 2012) in the sense of recognising non-academic knowledge only as far as it fits into the intellectual frameworks of academic researchers. In Lansing's case of water temples, local knowledge is validated through computational modelling according to which ritual practices established an optimal balance between concerns about water shortage and pest-spread. However, such an academic justification and validation will not always be feasible when engaging with religious and other local practices that are deeply embedded in Indigenous worldviews and ways of relating to environments. Even if academic researchers struggle to understand Indigenous knowledge due to this embedding of different worldviews, this knowledge is often crucial for local practices and sustainable relations to environments (Boogaard et al., forthcoming).

Demanding scientific validation in analogy to the Bali case therefore runs the risk of excluding large parts of Indigenous and local knowledge that does not easily integrate into academic frameworks due to its embedding in different epistemological, ontological, and value standpoints. A demand for validation also runs the risk of reproducing the basic asymmetry of epistemic paternalism as characterised in the last section. Often, the legitimacy of Indigenous and local knowledge is treated as dependent on its academic validation while the 
legitimacy of academic knowledge does not have to be proven in the light of Indigenous and local standards.

Deep differences between epistemological, ontological, and value standpoints limit simple integrationist agendas that appeal to Indigenous and local knowledge if it fits into frameworks of academic researchers. These complex relations beyond integration become especially pressing from the perspective of the 'politics of knowledge' that address the question of what knowledge is considered, what knowledge is seen as in need of validation, and in whose frameworks knowledge becomes integrated. Knowledge integration matters but needs to be positioned in a framework of critical transdisciplinarity that is reflexive about tensions and limits of integration in the negotiation of knowledge.

\section{Making transdisciplinarity work: the need for knowledge negotiation and transformative dialogues}

The limitations of a simple integrationism point towards two core challenges for 'making transdisciplinarity work' in the context of inclusive development and innovation. First, transdisciplinary processes need to move beyond an additive model of knowledge integration and address tensions that arise from diverging epistemologies, ontologies, and values (Ludwig and El-Hani, 2020). Second, critical transdisciplinarity requires a positive approach to knowledge negotiation that can respond to these limitations of integration and to power differentials between heterogeneous actors in transdisciplinary processes. Below, we will draw on two philosophical resources to address these challenges: philosophy of science and intercultural philosophy.

In developing an account of knowledge negotiation beyond a simple additive model of knowledge integration, it is helpful to start with the notion of 'trading zones' that has been introduced to the history and philosophy of science through Galison's (1997) Image and logic: A material culture of microphysics. Studying the development of high energy physics in the second half of the 20th century, Galison focused on laboratories as transdisciplinary negotiation spaces that involved scientists from a wide range of fields such as 'engineers, physicists, chemists, and metallurgists' (1997, p. 46), but that also included a wider range of actors, from public regulators to laboratory technicians. While Galison's context of modern physics contrasts with debates about inclusive development in the Global South, his analysis of the relation between knowledge and practice provides wider lessons for modelling transdisciplinary processes. Galison's analysis differs from simple integrationist narratives in characterising laboratories as transdisciplinary meeting grounds without assuming that underlying epistemological and ontological tensions were resolved through integration and consensus. In this sense, trading zones appear as 'an intermediate domain in which procedures could be coordinated locally even where broader meanings clashed' (1997, p. 46). In contrast to additive models of knowledge integration, Galison's trading zones are epistemically productive despite and sometimes because of 
unresolved tensions, by allowing actors to 'hammer out a local coordination, despite vast global differences [and] establish; contact languages, systems of discourse' (Galison, 1997, p. 783).

Framing transdisciplinary research in terms of trading zones helps to shift the focus from an additive model of knowledge integration to a focus on complex processes of knowledge negotiation. Of course, knowledge negotiation in development projects is very different from laboratories in high energy physics. One difference is the depth of epistemological and ontological tensions. In Galison's study, laboratory actors tend to share more background assumptions than in development contexts that bring up additional challenges of intercultural communication. In addition, many development projects operate in a (at least politically) post-colonial environment, which is another important reason why Galison's work on laboratories is so different from transdisciplinary development projects. Transdisciplinary development projects are full of unequal power relations that have their roots in colonial history, which makes the situation even more complex. Diverse ontologies and epistemologies in development projects do not meet by coincidence or in a vacuum, but the unequal relation between these ontologies is based on historical oppression by the Global North. In African philosophy it has been made clear that the false idea of ontological hierarchy between Africans and their former colonisers continues to influence Africa's international relations and the ongoing struggle for reason in Africa (Ramose, 2003).

In this line, the case study from Mozambique showed that despite 'good intentions' to make development and innovation processes more inclusive, epistemic paternalism and epistemic injustice remained persistent in practice. In an attempt to overcome this persistence of colonial legacies, we can learn from insights and approaches in intercultural philosophy as a way to move towards more equal epistemic relations. As mentioned before, the integrationist frame assumes knowledge exchange between equals, while knowledge negotiation emphasises that this process is always politically structured. In intercultural philosophy the importance of negotiation is also recognised as a way to create a proper place at the table (see Roothaan, 2019); in this case to have access to and participate in the trading zone. In addition, there is a need to bring diverse epistemologies, ontologies, and values into dialogue with each other. Thus, dialogues are an important approach in intercultural philosophy (Kimmerle, 2012).

There are at least three insights from intercultural dialogues that are relevant for transdisciplinarity. To start with, 'intercultural philosophical dialogues presuppose that the philosophies of all cultures are equivalent in rank and different in style as well as in content' (Kimmerle, 2011, p. 137). This does not mean there are no power differences between dialogue partners, but there is no pre-assumed ontological and epistemological hierarchy between them. Second, although intercultural dialogues can lead to mutual understanding, this may not always be reached (Kimmerle, 2011). Instead, “Erratic blocs” of misunderstanding will remain so that the method of these dialogues only partly can be a 
hermeneutical one' (Kimmerle, 2011, p. 139). This means that the question of to what extent it is possible to truly understand 'the other' requires attention, and there may be partial incommensurability between epistemologies, ontologies, and values. Third, intercultural dialogues require an open attitude which assumes that 'the others tell me something, which I could not have told me myself by any means' (Kimmerle, 2012). Thus, through intercultural dialogues, actors reflect on their own thinking, learn from others, and simultaneously influence others. In doing so, the involved actors as well as their philosophies are transformed. As such, intercultural dialogues are transformative dialogues. This means that engagement in transdisciplinary projects is not non-committal, but requires an openness and willingness of involved actors to be influenced and transformed by others.

Addressing transdisciplinary processes through trading zones and transformative dialogues allows the formulation of a descriptively and normatively more adequate approach. First, it is descriptively more accurate by locating successful cases of knowledge integration in a wider context of knowledge negotiation that also involves countless cases of partial understanding, misunderstanding, and tension. Second, such an account of complex knowledge negotiation is also normatively more adequate by highlighting contested processes of mutual interpretation and misinterpretation. Transdisciplinary research is not a neutral process of knowledge aggregation but raises normative questions about which interpretations prevail and how trading zones are institutionally structured. Third, transdisciplinarity processes are transformative processes in which all involved actors and their philosophies are transformed through intercultural dialogues.

\section{Conclusion}

The aim of this chapter has been to address the epistemological conditions of reimaging development and innovation. Rather than merely shifting targets towards societal and environmental goals, we have argued that inclusive development and innovation require an inclusive epistemology that is responsive to the knowledge diversity of heterogeneous actors. Transdisciplinarity promises such an inclusive epistemology; one that integrates diverse sources of academic and non-academic knowledge. Making transdisciplinarity work, however, is far from trivial. Most importantly, transdisciplinary research tends to emphasise an integrationist agenda that runs the risk of recognising the knowledge of nonacademic actors only insofar as it fits into frameworks of academic researchers. Overcoming the limitations of a simple integrationism requires recognition of the complexity of knowledge negotiation: we argue that a more realistic approach will have to address partly incommensurable epistemologies, ontologies, and values. Making transdisciplinarity work requires practices that create openings for knowledge integration as much as procedures for negotiating difference and engaging in transformative dialogues. 


\section{References}

Asher, K. and Wainwright, J. (2019). After post-development: On capitalism, difference, and representation. Antipode. Wiley Online Library, 51(1), 25-44.

Berkes, F. (2018). Sacred ecology: Traditional ecological knowledge and resource management. New York: Routledge.

Boogaard, B. K. (2019). The relevance of connecting sustainable agricultural development with African philosophy. South African Journal of Philosophy, 38(3), 273-286.

Boogaard, B. K. (2021). Epistemic injustice in agricultural development: Critical reflections on a livestock development project in rural Mozambique. Knowledge Management for Development Journal. 16(1), 28-54.

Boogaard, B. K., Ludwig, D., Guri, B. Y. and Banuoku, D. (forthcoming). A reconsideration of African spirituality in agricultural development projects: Traditional ecological knowledge from Dagara elders in Koro, Ghana. In: Roothaan, A., Bateye, B., Masaeli, M. and Müller, L. (eds.). Beauty in African thought: Critique of the Western idea of development. Washington: Lexington Books.

Blok, V. and Lemmens, P. (2015). The emerging concept of responsible innovation. Three reasons why it is questionable and calls for a radical transformation of the concept of innovation. In: Koops, B. J., Oosterlaken, I., Romijn, H., Swierstra, T. and Van den Hoven, J. (eds.). Responsible Innovation 2. Springer, 19-35.

Bhambra, G. K., Gebrial, D. and Nişancioğlu, K. (2018). Decolonising the university. London: Pluto Press.

Brown, V. A., Harris, J. A. and Russell, J. Y. (2010). Tackling wicked problems through the transdisciplinary imagination. London: Earthscan.

Byskov, M. F. (2020). Four challenges to knowledge integration for development and the role of philosophy in addressing them. Journal of Global Ethics, 16(3), 1-21.

Chataway, J., Hanlin, R. and Kaplinsky, R. (2014). Inclusive innovation: An architecture for policy development. Innovation and Development, 4(1), 33-54.

Cole, A. (2017). Towards an indigenous transdisciplinarity. Transdisciplinary Journal of Engineering \& Science, 8, 127-150.

Diao, X., Headey, D. and Johnson, M. (2008). Toward a green revolution in Africa: What would it achieve, and what would it require? Agricultural Economics, 39(supplement), $539-555$.

Escobar, A. (1991). Anthropology and the development encounter: The making and marketing of development anthropology. American Ethnologist, 18(4), 658-682.

Fricker, M. (2007). Epistemic injustice: Power and the ethics of knowing. Oxford: Oxford University Press.

Galison, P. (1997). Image and logic: A material culture of microphysics. Chicago: University of Chicago Press.

Gupta, J. and Vegelin, C. (2016). Sustainable development goals and inclusive development. International Environmental Agreements: Politics, Law and Economics. Springer, 16(3), 433-448.

Healy, H. (2019). A political ecology of transdisciplinary research. Journal of Political Ecology, 26(1), 500-528.

Heeks, R., Foster, C. and Nugroho, Y. (2014). New models of inclusive innovation for development. Milton Park: Taylor \& Francis.

Kidd, I. J., Medina, J. and Pohlhaus Jr, G. (2017). The Routledge handbook of epistemic injustice. Milton Park: Taylor \& Francis.

Kimmerle, H. (2011). Respect for the other and the refounding of society: Practical aspects of intercultural philosophy. In: Oosterling, H. and Ziarek, E. 
P. (eds.). Intermedialities: philosophy, arts, politics. Washington: Lexington Books, 137-152.

Kimmerle, H. (2012). Dialogues as Form of Intercultural Philosophy. Iranian Society of Intercultural Philosophy. http://isiph.ir/en/?p=27.

Klein, J. T., Grossenbacher-Mansuy, W., Häberli, R., Bill, A., Scholz, R. W. and Welti, M. (eds.) (2001). Transdisciplinarity: Joint problem solving among science, technology, and society: An effective way for managing complexity. Dordrecht: Springer Science \& Business Media.

Lansing, J. S. (2009). Priests and programmers: Technologies of power in the engineered landscape of Bali. Princeton: Princeton University Press.

Lawrence, R. J. (2015). Advances in transdisciplinarity: Epistemologies, methodologies and processes. Amsterdam: Elsevier.

Ludwig, D. and El-Hani, C. N. (2020). Philosophy of ethnobiology: Understanding knowledge integration and its limitations. Journal of Ethnobiology, 40(1), 3-20.

Ludwig, D. and Macnaghten, P. (2020). Traditional ecological knowledge in innovation governance: A framework for responsible and just innovation. Journal of Responsible Innovation, 7(1), 26-44.

Ludwig, D. and Poliseli, L. (2018). Relating traditional and academic ecological knowledge: mechanistic and holistic epistemologies across cultures. Biology \& Philosophy, 33(5-6), 43.

McMichael, P. (2015). Food regimes and agrarian questions. Agrarian change and peasant studies. Rugby: Practical Action Publishing.

OECD (2020). Addressing societal challenges using transdisciplinary research. Paris: OECD. https://doi.org/10.1787/0ca0ca45-en.

Pansera, M. and Owen, R. (2018). Framing inclusive innovation within the discourse of development: Insights from case studies in India. Research Policy, 47(1), 23-34.

Pohl, C., Truffer, B. and Hirsch Hadorn, G. (2017). Addressing wicked problems through transdisciplinary research. In: Frodeman, R., Klein, J. T. and Pacheco, R. C. D. S. (eds.). The Oxford handbook of interdisciplinarity, 319-331, Oxford: Oxford University Press.

Ramose, M. (2003). Introduction. The struggle for reason in Africa. In: Coetzee, P. H. and Roux, A. P. J. (eds.). The African philosophy reader. Second edition. Oxford: Oxford University Press, 1-9.

Roothaan, A. (2019). Indigenous, modern and postcolonial relations to Nature: Negotiating the environment. New York: Routledge.

Sachs, W. (1992). The development dictionary: A guide to knowledge as power. Hyderabad: Orient Blackswan.

Schmidt, L. and Pröpper, M. (2017). Transdisciplinarity as a real-world challenge: A case study on a North-South collaboration. Sustainability Science, 12(3), 365-379.

Scholz, R. W. and Steiner, G. (2015). Transdisciplinarity at the crossroads. Sustainability Science, 10(4), 521-526.

Siddiqi, A. and Collins, R. D. (2017). Sociotechnical systems and sustainability: current and future perspectives for inclusive development. Current Opinion in Environmental Sustainability, 24, 7-13.

Stilgoe, J., Owen, R. and Macnaghten, P. (2013). Developing a framework for responsible innovation. Research Policy, 42(9), 1568-1580.

Van der Ploeg, J. D., Renting, H., Brunori, G., Knickel, K., Mannion, J., Marsden, T., ... and Ventura, F. (2000). Rural development: From practices and policies towards theory. Sociologia Ruralis, 40(4), 391-408. 
Van der Ploeg, J. D. (2009). The new peasantries. Struggles for autonomy and sustainability in an era of empire and globalization. London: Earthscan.

Van der Ploeg, J. D. (2016). Theorizing agri-food economies. Agriculture, 6(30), 1-12.

Wiredu, K. (1995). Conceptual decolonization in African philosophy. Ibadan: Hope Publications.

Wiredu, K. (2003). The moral foundations of an African culture. In: Coetzee, P. H. and Roux, A. P. J. (eds.) (2015). The African philosophy reader. London: Routledge, 287-296. 